\title{
Stopping short of history
}

\section{John Dunster}

Chernobyl: The Real Story. By Richard F.

Mould. Pergamon: 1988. Pp. 256. Hbk $£ 25, \$ 45 ; p b k £ 9.95 \$ 17.95$.

An AUTHOR who chooses, or lets his publisher choose, the subtitle "the real story" sets himself a high standard of historical insight, especially when the story is necessarily filtered through the information system of the Soviet Union.

Some of the information released by the Soviet authorities about the accident at Chernobyl can be checked against environmental findings in Western Europe, but there is no real information about the events on site beyond that officially released. The large, and predominantly cynical, group of scientists and engineers who listened to the Soviet presentation in Vienna in late August, 1986, were impressed both by the Soviet delegation, led by Adademician Legasov, now regrettably dead, and by the amount of written detail that had been assembled in only four months. I doubt if we in the West could have done as well in that time. Nevertheless, although the information is consistent with the basic facts of reactor physics and engineering, we must remember that it is not subject to effective challenge. Much was left unsaid and the account given of some of the events sounded suspiciously tidy.

That is the background against which this book has to be judged. The key questions must be - Does it illuminate the Soviet story? Does it probe the weaknesses or ambiguities? And, finally, does it identify the lessons for the future? Unfortunately, the answers to all these questions seem to be 'no'.

So what did happen at Chernobyl and what does Richard Mould tell us about it? The accident started with a simple and useful experiment aimed at finding out how effective the kinetic energy of the turbo-alternators would be at providing a short period of emergency power if the station lost all internal and external sources of electricity. The experiment called for the reactor to be run at about half its rated power and for the steam valve to the turbine then to be closed. But several characteristics of the reactor and several silly mistakes by the operators made the experiment dangerous and eventually disastrous.

Chernobyl has boiling-water reactors with graphite moderators. They use the

same neutron-absorbing rods for control and shut down. The control of any reactor is greatly helped by a subtle property of the fission process. A small percentage of the fission neutrons are released after a delay of some seconds, rather than instantaneously. The reactor, in normal operation, has to wait for these delayed neutrons before it can increase power. But if neutron absorbers are withdrawn from the reactor very rapidly and to a sufficient extent, the reactor can go 'prompt critical' and gain power within milliseconds rather than the more usual seconds or minutes. This is still slow by the standards of nuclear explosions (microseconds or less) but it is much faster than the control

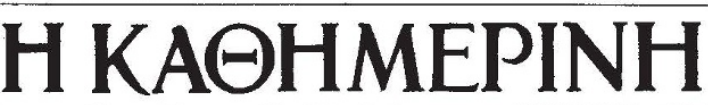

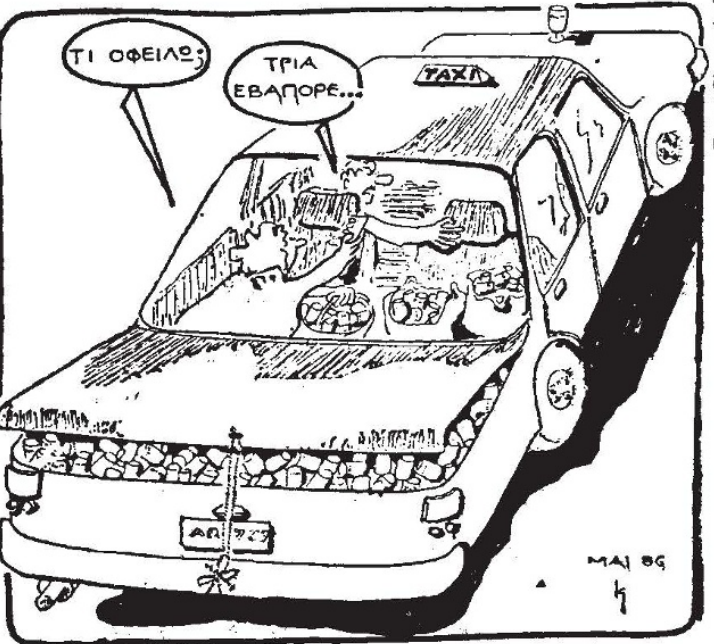

"How much?" - "Three evaporated milks". An Athens daily newspaper of 8 May 1986 caricatured the local population resorting to panic buying in the wake of Chernobyl.

cent to 100 times the maximum rated power in about four seconds. The resultant explosive interaction of the over-heated fuel with the cooling water shattered the reactor.

Mould describes this process qualitatively but fails to identify the main causes, especially prompt criticality, and to explain realistically the significance of the operator errors. For example, he notes that the emergency core-cooling system was turned off ("major fault no. 1") but doesn't say that the action was irrelevant to the initiation and development of the accident. He does not explain why the minimum insertion of the control rods was important. He omits the magnitude of the power surge. Later on, his description of the metabolic differences between iodine, caesium and strontium is confused and misleading.

Perhaps the detailed criticisms can be regarded as technical minutiae, of no concern to the general reader. So how good is the broader picture? The outstanding characteristic of the book is its remarkable coverage of the reported information. It is full of quotations from the Soviet and world press. As an example of data acquisition, it is unchallengeable, and errors, as such, are commendably few. But this is essentially a detective story, so the data have to be analysed, judged for veracity and completeness, and collated. Mould sometimes remarks on the sensationalism of the press reports but, for the most part, he quotes his sources uncritically. His account of the heroism of the fire fighters, for example, is not supplemented by any criticism of the lack of protective clothing

systems of reactors are designed to handle.

The Chernobyl reactors have two peculiarities. At low power, any increase in steam in the pressure tubes improves the neutron economy and increases the power of the reactor and thus the steam generation - a form of positive feedback. Also, the control rods are shut-off rods. A substantial and specified number of control rods have to be partially in the reactor core so that their movement has an immediate effect. For a variety of reasons, the experiment was started with the reactor at only 7 per cent of its rated power - well into the region of positive feedback - and with very few rods in the core. Automatic control equipment had been disconnected, some of it for no obvious reason. When the steam valve was shut, more steam was generated in the pressure tubes, the power rose, aided by the positive feedback, the control and shut-down system was far too sluggish, and the reactor went prompt critical. A computer simulation, compatible with the physical consequences, suggests that the power went from 7 per and monitoring.

More gravely, he fails to organize his material coherently. His opening chapter on the power plant fails to identify the weaknesses of design while including extraneous detail. His short chapter on Kiev plunges without warning into the consequences of the previously unmentioned accident. His chapter on evacuation contains the data on the percentage releases from the core and the arrangements for medical follow up; these do not appear in the account of the accident or in the chapter entitled "Follow-up".

The book is liberally illustrated, but the selection of pictures has been uncritical; about half of them could have been omitted without loss. Apart from the chapter on the entombment of the reactor, which is clear and impressive, Chernobyl should be treated as an uncorrelated source of (largely) unconfirmed data. This is not "the real story".

John Dunster, 52 Thames Street, St Ebbes, Oxford OXI ISU, UK, was formerly Director of the National Radiological Protection Board. 